\title{
A Suitability Study of the Fission Product Phantom and the Bottle Manikin Absorption Phantom for Calibration of In Vivo Bioassay Equipment for the DOELAP Accreditation Testing Program
}

P. C. Olsen

T.P. Lynch

August 1991

Prepared for the U.S. Department of Energy under Contract DE-AC06-76RLO 1830

Pacific Northwest Laboratory

Operated for the U.S. Department of Energy by Battelle Memorial Institute 


\title{
DISCLAIMER
}

This report was prepared as an account of work sponsored by an agency of the United States Government. Neither the United States Government nor any agency thereof, nor Battelle Memorial Institute, nor any of their employees, makes any warranty, expressed or implied, or assumes any legal liability or responsibility for the accuracy, completeness, or usefulness of any information, apparatus, product, or process disclosed, or represents that its use would not infringe privately owned rights. Reference herein to any specific commercial product, process, or service by trade name, trademark, manufacturer, or otherwise does not necessarily constitute or imply its endorsement, recommendation, or favoring by the United States Government or any agency thereof, or Battelle Memorial Institute. The views and opinions of authors expressed hercin do not necessarily state or reflect those of the United States Government or any agency thereof.

\author{
PACIFIC NORTHWEST LABORATORY \\ operated by \\ BATTELLE MEMORIAL INSTITUTE \\ for the \\ UNITED STATES DEPARTMENT OF ENERGY \\ under Contract DE-ACO6-76RLO 1830
}

Printed in the United States of America

Available to DOE and DOE contractors from the

Office of Scientific and Technical Information, P.O. Box 62, Oak Ridge, TN 37831;

prices available from (615) 576-8401. FTS 626-8401.

Available to the public from the National Technical information Service, U.S. Department of Commerce, 5285 Port Royal Rd., Springfield, VA 22161. 


\section{DISCLAIMER}

This report was prepared as an account of work sponsored by an agency of the United States Government. Neither the United States Government nor any agency Thereof, nor any of their employees, makes any warranty, express or implied, or assumes any legal liability or responsibility for the accuracy, completeness, or usefulness of any information, apparatus, product, or process disclosed, or represents that its use would not infringe privately owned rights. Reference herein to any specific commercial product, process, or service by trade name, trademark, manufacturer, or otherwise does not necessarily constitute or imply its endorsement, recommendation, or favoring by the United States Government or any agency thereof. The views and opinions of authors expressed herein do not necessarily state or reflect those of the United States Government or any agency thereof. 


\section{DISCLAIMER}

Portions of this document may be illegible in electronic image products. Images are produced from the best available original document. 
P. C. 01 sen

T. P. Lynch

J. C. McDonald, PNL Project Manager

J. M. Selby, PNL Program Manager

August 1991

Prepared for

the U.S. Department of Energy

under Contract DE-AC06-76RLO 1830

Pacific Northwest Laboratory

Richland, Washington 99352 


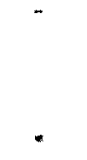




\section{SUMMARY}

Pacific Northwest Laboratory (PNL) conducted an intercomparison study of the Fission Product phantom and the bottle manikin absorption (BOMAB) phantom for the U.S. Department of Energy (DOE) to determine the consistency of calibration response of the two phantoms and their suitability for certification and use under a planned bioassay laboratory accreditation program. The study was initiated to determine calibration factors for both types of phantoms and to evaluate the suitability of their use in DOE Laboratory Accreditation Program (DOELAP) round-robin testing.

The (BOMAB) phantom and the Fission Product phantom were used to simulate detection of radionuclides incorporated in the whole body. The test radionuclides were first loaded in the phantoms and then measured on PNL whole body counting equipment to determine calibration factors. The resulting data were compared with PNL calibrations and with previous human data. Characteristics of the phantoms' ease-of-use were also evaluated, because DOELAP testing wi11 require a durable and reliable calibration standard.

The results of quantitative testing demonstrated that there were large differences of up to $30 \%$ between the in vivo detection system responses to the two phantom types. Detector response to the Fission Product phantom was lower than the BOMAB phantom on all the in vivo counting systems used. Measurements of the detector response to the linear distribution of activity in the phantoms demonstrated that the Fission Product phantom causes detector response to vary widely over the length of the phantom. Comparing the phantoms with earlier human studies of persons having known amounts of radioactivity demonstrated that the Fission Product phantom had a similar calibration factor to these human calibrations.

Evaluation of the use and handling characteristics of the phantoms showed limitations to the durability and the radionuclide source loading capabilities of the Fission Product phantom. The BOMAB phantom polyurethane fill material bubbled and produced air voids during construction, leading to non-uniform activity distributions. However, the inclusion of more stringent production and testing methods would reduce the problems observed in this study. The 
conclusion of this study was that the BOMAB phantom was found to be more appropriate for the DOELAP testing program. 


\section{ACKNOWLEDGMENTS}

The authors would like to acknowledge the assistance of Mr. Gunars Reiksts for much of the calibration and measurement work done at the In Vivo Radioassay and Research Facility at Pacific Northwest Laboratory, Dr. D. R. Fisher for peer reviewing the report, S. K. Ennor for editing, and M. Cross for text processing. 


\section{CONTENTS}

SUMMARY

ACKNOWLEDGMENTS

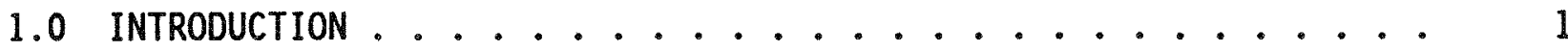

1.1 BACKGROUND ............................... 1

1.2 PREVIOUS WORK ......................... 3

2.0 PHANTOM CONSTRUCTION AND CALIBRATION . . . . . . . . . . . 5

2.1 FISSION PRODUCT PHANTOM . . . . . . . . . . . . 6

2.2 ВОМАВ РНANTOM ......................... 10

3.0 MEASUREMENT INTERCOMPARISON METHODS . . . . . . . . . . . 15

3.1 QUANTITATIVE MEASUREMENTS . . . . . . . . . . . 15

3.1.1 Coaxial Germanium Detector Array . . . . . . . 15

3.1 .2 Vertical Array of Five $\mathrm{NaI}(\mathrm{Tl})$ Detectors
(Standup Counter) . . . . . . . . . . 16

3.1.3 Shadow Shield NaI Scanning Bed . . . . . . . . 18

3.2 DIFFERENTIAL LINEAR SCANNING . . . . . . . . . . . 19

3.2.1 Five NaI(TI) Detector Vertical Array . . . . . . 19

3.2.2 Collimated 4-in.-by-4-in.-by-16-in. NaI Scanning Bed . 20

4.0 RESULTS OF INTERCOMPARISON TESTS . . . . . . . . . . . . 21

4.1 QUANTITATIVE RESULTS . . . . . . . . . . . . 22

4.2 DIFFERENTIAL LINEAR SCAN RESULTS . . . . . . . . . . 25

4.3 PHYSICAL DURABILITY AND DESIGN . . . . . . . . . . . 29

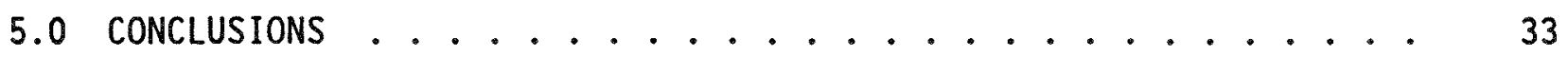

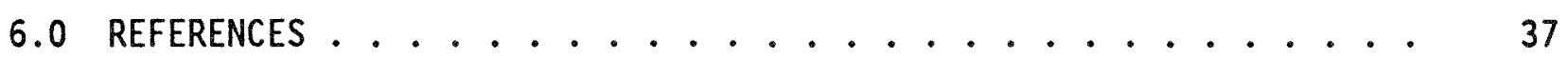




\section{FIGURES}

1 The Fission Product Phantom in the Shadow Shield Scanning Bed ................... 7

2 Source Capsules for Loading the Fission Product Phantom .... 9

3 The Bottle Mannikin Absorption Phantom .......... 11

4 The Scanning Coaxial Germanium Detector Array . . . . . . . 16

5 The Standup Counter with Counting Position (Inset) . . . . 17

6 The Shadow Shield Scanning Bed ............. 18

7 Response of Standup Counter to Four Measured Regions of

(a) the BOMAB Phantom, (b) the Fission Product Phantom, and

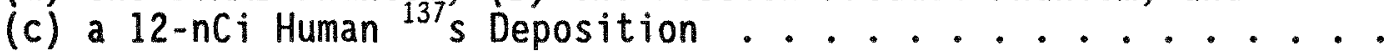

8 Collimated Linear Scan of the ${ }^{154} \mathrm{Eu}(1274-\mathrm{keV})$ BOMAB Phantom .. . 30

9 Collimated Linear Scan of the ${ }^{154}$ Eu Fission Product Phantom . . . 30

\section{TABLES}

1 Radionuclide Content of Capsule Sources in Fission

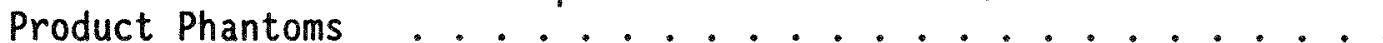

2 Measurements of Poly Bottles in a BOMAB Phantom

Representing Human Body Parts ............. 12

3 BOMAB Phantom Radionuclide Activities ........... 14

4 Calibration Factors Used for PNL Whole Body

Counting Systems ..................

5 Calibrations and Comparison of Counting Efficiency with Body Size Using the Shadow Shield Counter. . . . . . . 22

6 Detector Results for Phantoms Loaded with ${ }^{137}$ Cs . . . . . . . . . 23

7 Results of the ${ }^{154} \mathrm{Eu}$ Radionuclide Phantom Comparison Using a 1274-keV Photon ................. 23

8 Results of the ${ }^{40} \mathrm{~K}$ Radionuclide Phantom Comparison ... . . . . 24

9 Percent Activity in Body Regions of Two Phantoms and Humans . . 26 


\subsection{INTRODUCTION}

Pacific Northwest Laboratory (PNL) ${ }^{(a)}$ provides technical assistance to the U.S. Department of Energy (DOE) and the Radiological and Environmental Sciences Laboratory (RESL) in Idaho Falls for the conduct of an in vivo bioassay Department of Energy Laboratory Accreditation Program (DOELAP). As part of this assistance, PNL performed a study to evaluate two candidate calibration phantoms to be used in DOELAP testing. Part of this work also entailed comparing in vivo detector calibration response of the phantoms with known human calibration factors determined in a previous study, thereby providing a measure of the accuracy of the phantoms' response (Palmer and Roesch 1965). These two commercially available, anthropomorphic calibration phantoms were specifically designed for use with radionuclides that distribute evenly throughout the soft tissues of the body. This study was conducted in support of DOE's initiative to standardize and cross-calibrate its own and DOEcontractor bioassay laboratories. Its purpose was also to provide reliable, standardized calibration phantoms for successful development and implementation of an accreditation program for in vivo measurements at those 1aboratories.

\subsection{BACKGROUND}

The determination of radionuclide organ burdens in occupational workers has historically required calibration of the analysis equipment used for detecting various radioactive emissions from the body. The use of in vivo bioassay instrumentation has been tested in several DOE studies for the purpose of standardizing the calibrations of various laboratories (MacLellan et a1. 1990; Robinson et al. 1986). These intercomparison studies involving U.S. laboratories have shown wide variation in the capabilities of in vivo laboratories to measure radionuclides in standard test phantoms.

The use of different types of calibration phantoms and the use of different tissue-substitute materials have contributed to the variation in

(a) Pacific Northwest Laboratory is operated for the U.S. Department of Energy by Battelle Memorial Institute under Contract DE-AC06-76RLO 1830. 
measured activities of calibration standards between 1aboratories performing in vivo measurements. The appropriateness of the calibration standards and materials used in these testing programs has been questioned because of the failure rate of some laboratories. The materials used, the construction techniques, and the overall reliability of calibration phantoms can be major factors in obtaining a reliable calibration (ICRU 1989). The most suitable materials should be used in the construction of phantoms, for instance, for a given radiation energy and type, and the material should have radiation absorption and scattering properties that are similar to those for human irradiated tissue (within known acceptable limits).

DOE is currently planning the standardization and cross-calibration of various DOE and contractor bioassay laboratories using an accreditation program similar to the DOELAP accreditation program used for external dosimetry (DOE 1989). PNL is designing and preparing phantoms for RESL to use in a pilot accreditation program for DOE bioassay laboratory certification.

Reliable, standardized calibration phantoms are needed to successfully implement an accreditation program. Standardized phantoms will assure that variation in DOE laboratory calibrations, due to inconsistencies in the phantoms, are minimized. The American National Standards Institute Standard N13.30 (ANSI 1989) requires that the phantom to be used in testing for the whole body category be commercially available to the service laboratory. The calibration phantom used in round-robin testing should also have a long shelflife (within inherent radionuclide decay limitations) to sustain 1 aboratory calibrations and ultimately to support the DOELAP accreditation testing program. Both the Fission Product phantom and BOMAB phantoms meet these two criteria. Other factors, such as the durability, repeatability of source loading, and uniformity of test radionuclides, also need to be considered in an acceptable phantom by analysis of phantom characteristics. These factors contribute to the uncertainty in calibrations. 


\subsection{PREVIOUS WORK}

The intercomparison study described in this report was developed from previous work with phantom types that identified certain inconsistencies in phantom properties, such as photon transmission, distribution of radionuclide sources, and the presence or absence of various anthropomorphic details (MacLel1an, Traub, and 01sen 1990; Robinson et al. 1986; Scherpe1z and MacLellan 1987). PNL previously completed a set of in vivo bioassay laboratory comparisons to test the adequacy of draft ANSI N13.30 using the BOMAB phantom for whole body measurements of ${ }^{137} \mathrm{Cs},{ }^{134} \mathrm{Cs},{ }^{60} \mathrm{Co},{ }^{144} \mathrm{Ce}$, and with interference radionuclides ${ }^{(a)}$ included (MacLellan, Traub, and 01 sen 1990).

Phantoms produced for this previous study were made using the BOMAB phantom design. The radionuclides were incorporated into a gelatin mixture to stabilize the radionuclide distribution in the phantom, and to facilitate removal of the fill material at the end of the program. This also reduced the potential for leakage during use or transport of the phantoms. Food coloring was used to provide an indication of uniform mixing. After an extended period of time, during which the phantom had been subjected to various environmental conditions, the growth of an algal matter was noted. A growth inhibitor (benzalkonium chloride) was used to retard this growth, and sodium metabisulfate was added to retard oxidation of the gelatin. A breakdown of the gelatin can still occur over extended time periods or under adverse temperature conditions, causing a non-homogeneous fluid to form in the bottles. For this reason a new substance needed to be used for the fill material.

Testing of the two phantom types was originally undertaken at PNL to calibrate the new version of the torso phantom (the Fission Product phantom) to the existing BOMAB phantom calibration. PNL tested BOMAB phantoms extensively with various materials filling the polyethylene bottles, and when RESL (as the DOELAP testing laboratory) chose the Fission Product phantom for preliminary testing, a calibration of the two phantoms became necessary. Recent changes in phantom design have raised the question of which is the best

(a) These radionuclides are not to be quantified by the testing laboratory. The radionuclides ${ }^{54} \mathrm{Mn}$ and ${ }^{60} \mathrm{Co}$ were used in the whole body category. 
phantom type to use in an intercomparison testing program. This study will assist in resolving this question and determining phantom needs for DOE. 


\subsection{PHANTOM CONSTRUCTION AND CALIBRATION}

The use of calibration phantoms containing radionuclide standards that simulate the location and transmission characteristics of radionuclides in an actual human body is part of a developing area of research ${ }^{(a)}$ (Griffith et a). 1978). Such anthropomorphic phantoms vary in complexity. The degree of detail can give a calibration phantom versatility that is often necessary when intercomparing laboratories that may have various geometries and equipment configurations. From very simple solid-geometry sources, such as bags of sugar and polyethylene blocks, to sophisticated articulated body representations, the achievement of accurate and representative phantoms has been pursued as a goal to improve calibrations.

Some of the more significant developments in calibration phantom design for gamma-emitting radionuclides have been the use of water-filled phantoms, such as the radiation-equivalent-mannikin-absorption phantom (REMAB) and the BOMAB phantom; and solid point-source phantoms, such as the Lawrence Livermore National Laboratory (LLNL) torso phantom.

Further development of the LLNL torso phantom by commercial manufacturers produced the Realistic ${ }^{(b)}$ torso phantom, which is essentially a commercial version of the LLNL torso phantom with different polymer components, having similar transmission characteristics, but with some structural changes. The Realistic phantom does not have a pelvis, a complete set of vertebrae, or distal ends of the scapulae. Overall shape changes in the torso included a very barrel-shaped chest and a squared-off back, somewhat thicker in overlying tissue than the typical living human. The Fission Product phantom was developed from the Realistic torso phantom by adding articulated limbs and a head to the Realistic phantom and including a more complete skeleton. The Fission Product phantom is intended for use with radionuclides that are incorporated in tissues of the whole body, rather than in just the internal organs of the torso cavity.

\footnotetext{
(a) Andreaco, M. S., and Byars, L. G. 1985. "Effects of Elemental Percentages and of Trace Element Contaminants on the Mass Attenuation Coefficients of Polyurethane-Based Tissue-Equivalent Materials." EG\&G Ortec, Oak Ridge, Tennessee.

(b) Manufactured by Radiology Support Devices, Inc., Long Beach, California.
} 


\subsection{FISSION PRODUCT PHANTOM}

The Fission Product phantom is an extension design of the LLNL torso phantom (Griffith et a1. 1978) produced to measure transuranic radionuclides in the lung and torso. A commercial version of the LLNL torso phantom, the Realistic phantom, was produced using a different mold for the torso. The dimensions of the torso were different from the LLNL design and noticeable changes in the inclusion of bones were made. The current Realistic and Fission Product phantom series are produced by Radiology Support Devices and has incorporated some of the missing features that the earlier Realistic torso phantom removed from the LLNL torso design. The Fission Product phantom has more a complete vertebral column and scapulae. These anatomical inclusions become important when certain counting geometries are utilized.

The Fission Product phantom modification incorporated a choice of 1 imbs that were attached to the torso phantom for analyzing radionuclides that distribute throughout the tissues of the body. The limbs were manufactured of the same tissue-substitute as the torso and incorporated a hole matrix to allow for insertion of capsule sources within the limbs.

Figure 1 shows the overall dimensions of the Fission Product phantom, placed in the shadow shield scanning bed. The phantom can be purchased with simulated bone in the extremities, and it has the versatility to be useful in simulating organ or whole body radionuclide burdens with use of special hollow organ inserts. A discrete source geometry can be produced either by filling the hollow organs with test solutions or by using discrete capsule sources placed in a hole matrix drilled throughout the limbs and organs of the phantom.

Two Fission Product phantoms were purchased from Radiology Support Devices to evaluate their consistency and measurement accuracy under a DOELAP accreditation program for in vivo bioassay laboratories. The appendages were solid and had a series of holes with solid Adaprene ${ }^{(a)}$ plugs inserted in them. This is the same material used to make the body phantom, albeit with differing calcium carbonate $\left(\mathrm{CaCO}_{3}\right)$ content to simulate the radiation

(a) Adaprene is a product name for tissue-equivalent material produced by Radiology Support Devices, Long Beach, California. 
interaction coefficients of different body tissues. Two sets of internal organs for the phantom were purchased. The first was a set of solid organs, of the tissue-substitute Adaprene with a hole matrix in each organ; and the second was a set of hollow plastic organs (liver, kidneys, spleen, pancreas, and stomach) that could be filled with test radionuclide solutions. In keeping with the use of the phantom in a round-robin intercomparison, where it would be shipped to various laboratories in the United States, the use of liquid radioactive sources is discouraged due to past experience of leaking,

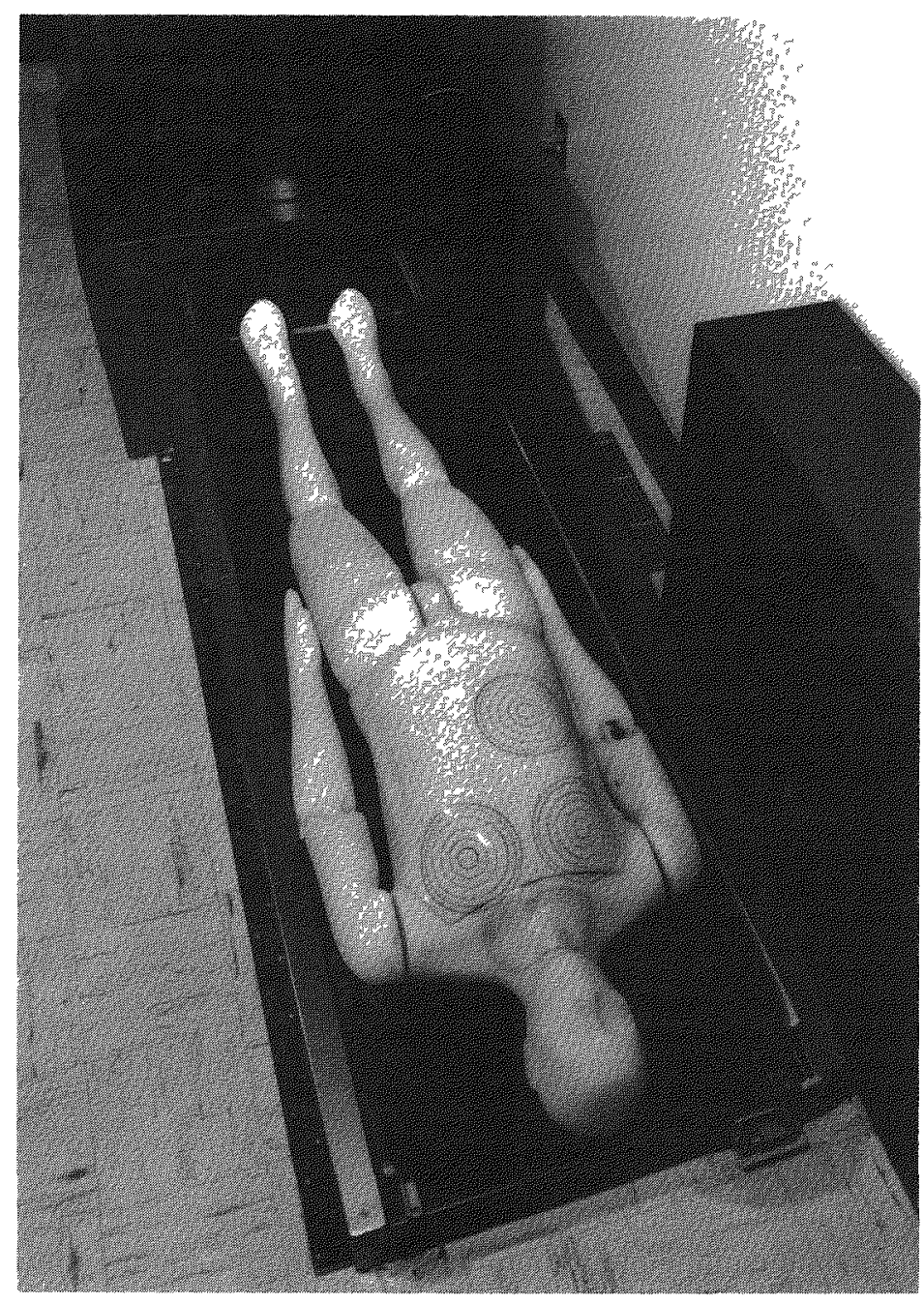

FIGURE 1. The Fission Product Phantom in the Shadow Shield Scanning Bed 
freezing, and foreign materials growing in the solution. Consequently, it was determined by PNL that only the solid organs were appropriate for testing the phantom.

Discrete capsule sources were produced by PNL's Materials and Chemicals Applications Department using the appropriate standard reference material (SRM) radionuclide solutions (as defined by the National Institute of Standards and Technology [NIST]). These solutions were diluted (by less than a $10^{3}$ factor) and absorbed onto filter papers. Each filter paper was then measured and placed in the Adaprene vial and the vial was sealed with isocyanide adhesive. The radionuclide content of each capsule source and the total activity in each of the two phantoms measured are listed in Table 1.

A set of 44 capsules containing test radionuclides was incorporated in the first Fission Product phantom. Each capsule contained ${ }^{125} \mathrm{Sb},{ }^{154} \mathrm{Eu}$, and ${ }^{155} \mathrm{Eu}$. The placement of the source capsules in each Fission Product phantom was based on uniform mass. The proportion of each body section weight to the total weight of the phantoms was used to estimate the number of capsules to place in each section. This resulted in a source distribution of $50 \%$ to the torso (including internal organs) and $50 \%$ to the 1 imbs. In addition, 344 capsules of dehydrated potassium carbonate $\left(\mathrm{K}_{2} \mathrm{CO}_{3}\right)$ were loaded into the $\mathrm{Eu} / \mathrm{Sb}$ phantom to produce an activity level of $\approx 100 \mathrm{nCi}{ }^{40} \mathrm{~K}$, evenly distributed throughout the phantom and proportional to the mass of the phantom parts. The 44 sources in the Eu/Sb phantom were used because the 344 capsules of $\mathrm{K}_{2} \mathrm{CO}_{3}$ necessary to produce the ${ }^{40} \mathrm{~K}$ burden left a significantly reduced number of holes available for placing test radionuclide capsules in the phantom. Evidently, there is no simple method to assure a uniform distribution when using the Fission Product phantom. A method that requires less of the available matrix for ${ }^{40} \mathrm{~K}$ is needed to allow for test source locations to have sufficient variability. For the subsequent Fission Product phantom containing ${ }^{137} \mathrm{Cs}$, the ${ }^{40} \mathrm{~K}$ burden was left out to allow for greater ability to locate source capsules in more areas of the phantom. The source capsules and the ${ }^{40} \mathrm{~K}$ fill are shown in Figure 2.

The primary purpose of these tests was to determine whether the phantom response was uniform and similar to known human response at levels well above the minimum detectable activity (MDA). Thus, even though required by draft 
TABLE 1. Radionuclide Contents in Fission Product Phantoms

\begin{tabular}{|c|c|c|c|c|c|}
\hline \multirow[b]{2}{*}{$\begin{array}{l}\text { Phantom } \\
\text { No. } \\
\end{array}$} & \multirow[b]{2}{*}{$\begin{array}{l}\text { Radionuclide } \\
\& \text { SRM Number } \\
\end{array}$} & \multirow{2}{*}{$\begin{array}{c}\text { No. of } \\
\text { Source } \\
\text { Capsules } \\
\end{array}$} & \multicolumn{3}{|c|}{ Activity } \\
\hline & & & $\begin{array}{l}\text { nci per } \\
\text { capsule } \\
\end{array}$ & $\begin{array}{l}\text { nCi per } \\
\text { Phantom } \\
\end{array}$ & $\begin{array}{c}\text { Reference } \\
\text { Date } \\
\end{array}$ \\
\hline 1 & $\begin{array}{c}{ }^{137} \mathrm{Cs} \\
(\mathrm{SRM}-4200-168)\end{array}$ & 75 & $4.12 \pm 0.10$ & $309 \pm 7$ & $03-07-90$ \\
\hline 2 & ${ }^{125} \mathrm{Sb}$ & & $3.79 \pm 0.01$ & $166.89 \pm 0.44$ & $03-07-90$ \\
\hline & ${ }^{154} \mathrm{Eu}$ & 44 & $6.72 \pm 0.01$ & $295.63 \pm 0.44$ & " \\
\hline & $\begin{array}{c}{ }^{155} \mathrm{Eu} \\
(\text { SRM-4276C-17) }\end{array}$ & & $2.10 \pm 0.01$ & $92.39 \pm 0.44$ & $"$ \\
\hline 3 & ${ }^{40} \mathrm{~K}$ & 344 & & $96 \pm 8$ & $04-01-90$ \\
\hline
\end{tabular}

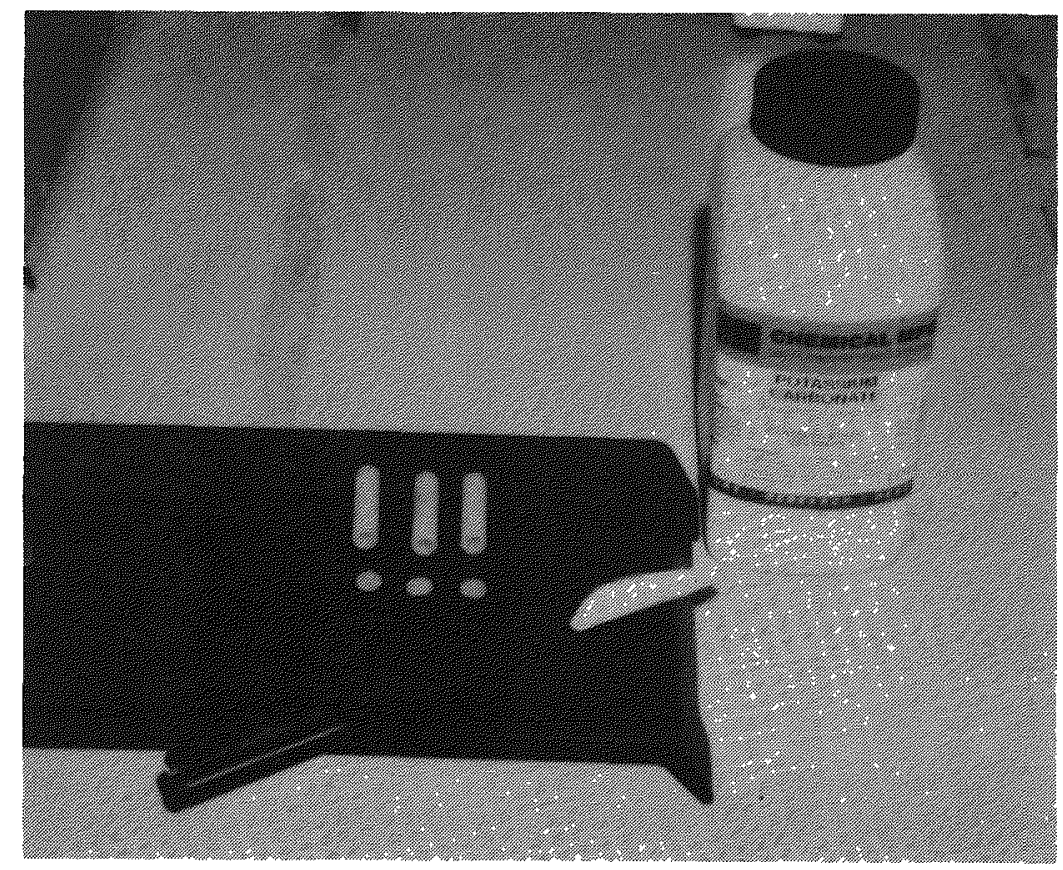

FIGURE 2. Source Capsules for Loading the Fission Product Phantom

ANSI N13.30 for testing MDA levels of laboratories, the fact that the second Fission Product phantom did not include any ${ }^{40} K$ activity was not an important factor. This phantom was loaded with 75 capsule sources of ${ }^{137} \mathrm{Cs}$ to simulate the whole body distribution of cesium in humans. As in the Eu/Sb Fission Product phantom, the sources were loaded proportionally to the mass of the phantom parts, in order to best simulate a uniform distribution. 
Variations in determining the background under the peak of interest were not significant when the activity was on the order of $10^{3}$ above the MDA. Since the phantom response at minimum detectable levels was not of interest in this study, the contribution to the background continuum from scattered ${ }^{40} \mathrm{~K}$ photons was insignificant. Using 75 discrete sources of ${ }^{137} \mathrm{Cs}$ also allowed for more versatility and a more uniform distribution within the phantom than the 44 discrete sources used in the Eu/Sb phantom.

The distribution in each organ or limb component was determined by a simple ratio of the number of capsules to the number of matrix holes for each component, with correction for large body areas that had no hole matrix -such as the head. In this region, the distribution in the rest of the upper torso was increased slightly to compensate for the inability to place any source capsules in the head area. Based on the potassium content of the brain, 3\% to $4 \%$ of cesium would be distributed in the head (ICRP 1974).

Each capsule was centered in the body component and the removed Adaprene blank plugs were replaced on each side of the source capsule. This completed the source loading and the phantom was ready for the measurement regime.

\subsection{BOMAB PHANTOM}

The BOMAB phantom was designed specifically for use in measuring internally deposited radioactive materials that are considered to be homogeneously distributed in the body and that emit high-energy photons. Figure 3 depicts the BOMAB phantom in a set-up condition. The 10 sections that make up the phantom are of various sizes and shapes. They approximate the whole body proportions of an adult Caucasian male of average stature, and roughly match the measurements of Reference Man as stated in Publication 23 of the International Commission on Radiological Protection (ICRP 1974). Each piece is a molded polyethylene canister with a screw top for filling with radionuclide test solutions. The sections can then be filled with liquid or gel materials. This emulates the uniform distribution of radiocesium and other radionuclides distributed in the whole body, while incorporating them in a water or simulated tissue-equivalent matrix. 


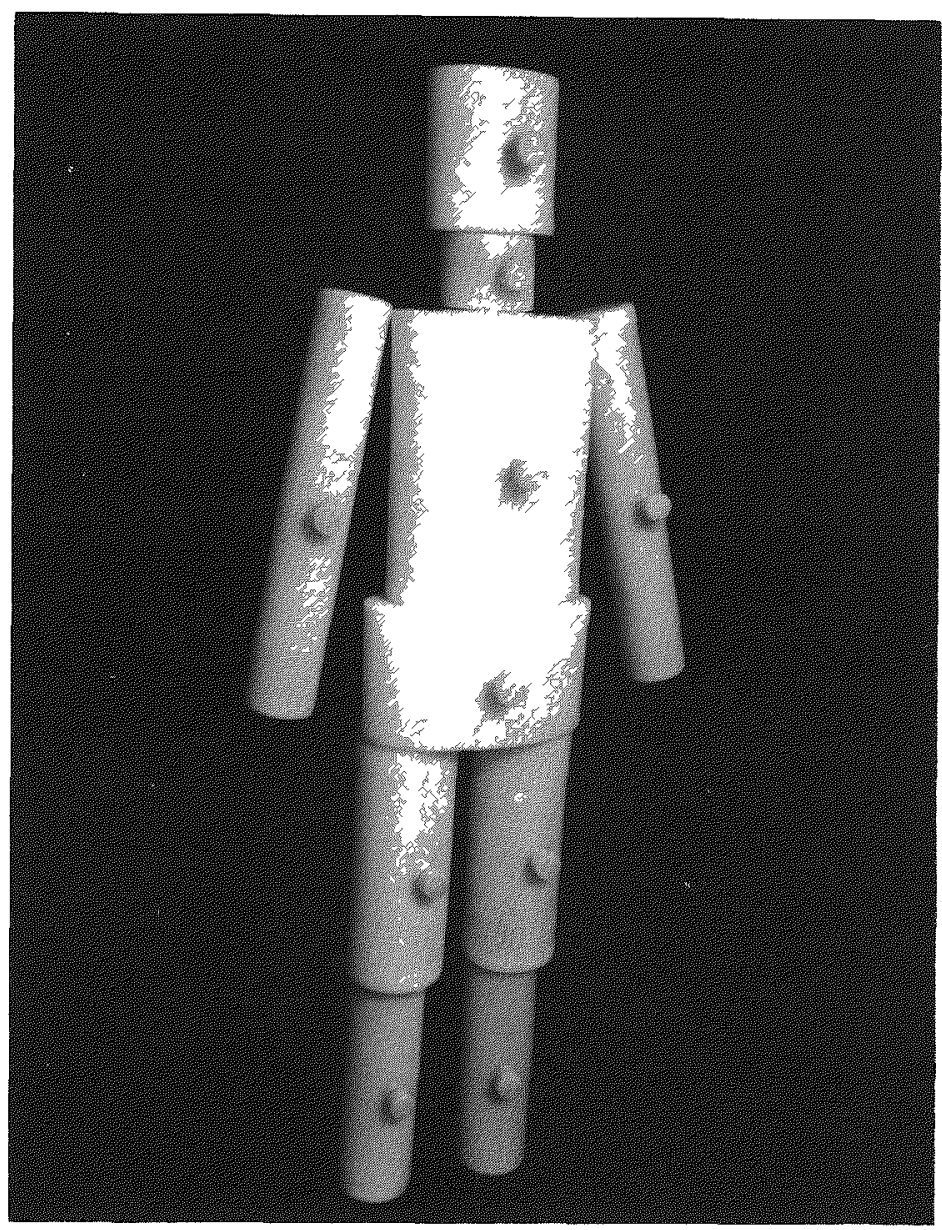

FIGURE 3. The Bottle Mannikin Absorption Phantom

Three BOMAB phantoms were purchased from Atlan-Tech, Inc., (Roswe11, Georgia). Each phantom consisted of 10 cylinders, manufactured of $4.76-\mathrm{mm}$ thick high-density polyethylene. The dimensions of the phantom sections are listed in Table 2. The phantom sections were filled with a commercially available polyurethane (Hysol TM $70 \mathrm{D}^{(\mathrm{a})}$ ), whose elemental composition was $\mathrm{H}-9.0 \%, \mathrm{C}-65 \%, \mathrm{~N}-9.4 \%$, and $0-15.5 \%$ (wt\%).

Commercially available polyurethane was chosen as the radionuclidebearing fill material because of its good tissue-substitute properties (Griffith et a1. 1978) and its durability. Using polyurethane precluded any leakage of test solutions from the polyethylene bottles. Using polyurethane

(a) Manufactured by Dexter Electronic Materials Division, 0lean, New York. 
TABLE 2. Measurements of Poly Bottles in a BOMAB Phantom Representing Human Body Parts

\begin{tabular}{|c|c|c|c|c|c|}
\hline $\begin{array}{l}\text { Simulated } \\
\text { Body Part }\end{array}$ & Shape & $\begin{array}{c}\text { Cross } \\
\text { Section }(\mathrm{cm})\end{array}$ & $\begin{array}{l}\text { Vertical } \\
\text { Height }(\mathrm{cm})\end{array}$ & $\begin{array}{c}\text { Fill } \\
\text { Volume (cc) }\end{array}$ & $\begin{array}{c}\text { Filled } \\
\text { Weight }(g)\end{array}$ \\
\hline Head & Ellipsoid & $19 \times 14$ & 20 & 3,525 & 4,363 \\
\hline Neck & Cylinder & 13 (diam) & 10 & 1,030 & 1,318 \\
\hline Thorax & Ellipsoid & $30 \times 20$ & 40 & 16,970 & 20,560 \\
\hline Pelvis & Ellipsoid & $36 \times 20$ & 20 & 9,990 & 11,760 \\
\hline Thighs(2) & Cylinder & 15 (diam) & 40 & 12,100 & 15,532 \\
\hline Legs (2) & Cylinder & 12 (diam) & 40 & 7,490 & 10,835 \\
\hline $\operatorname{Arms}(2)$ & Cylinder & 10 (diam) & 60 & 7,600 & 10,027 \\
\hline Total & & & 170 & 58,705 & 74,395 \\
\hline
\end{tabular}

also precludes any growth of algae or molds in the bottles or the expansion of the water with freezing. All three of these problems have been noted in previous uses.

$\mathrm{CaCO}_{3}$ was mixed with the polyurethane at $4.3 \mathrm{wt} \%$ to simulate of the radiation interaction properties of lean muscle (Griffith et a1. 1978). The electron density and effective atomic number for the polyurethane are 3.25 $E+23$ electrons $/ g$ and $A=6.11$, respectively; for the polyurethane mixed with $4.3 \mathrm{wt} \% \mathrm{CaCO}_{3}$, the respective values are $3.30 \mathrm{E}+23$ electrons $/ \mathrm{g}$ and $\mathrm{A}=7.16$.

The two-component polyurethane was mixed in 300 to $1600 \mathrm{~g}$ batches to fill sections of the BOMAB phantom poly bottles. Part $\mathrm{A}$ was mixed with $\mathrm{CaCO}_{3}$, which was ground to a fine powder prior to mixing with the test radionuclide(s), and $15 \mathrm{~mL}$ of acetone. The small amount of acetone was added as a carrier to facilitate uniform mixing and to increase the hardening time for the polyurethane. The polyurethane, radioactive material, $\mathrm{CaCO}_{3}$, and acetone were mixed in quart cans and transferred to the phantom. The ${ }^{137} \mathrm{Cs}$ and Eu/Sb SRMs were diluted to $250 \mathrm{~mL}$ in a volumetric flask and dispensed from a burette. Then four parts by weight of Part $A$ were mixed with one part of Part B. 
An exothermic reaction occurs when the two components are mixed. The smaller batch size required 5 to 10 minutes for cooling and the larger batch size required 15 to 20 minutes for cooling to minimize the formation of gas cavities. The procedure consisted of filling each BOMAB section with the batch, letting the curing reaction start, and then continuing the batches until the section was full.

Test batches of the Hysol polyurethane were made to measure the uniformity of activity distribution in the hardened sample. The test samples were approximately $1 \mathrm{in}$. thick and 6 in. in diameter. Each sample was cut into five sections and the activity concentration (counts/gram) for each section was determined. The coefficient of variation for the sample results ranged from $1.1 \%$ to $4.2 \%$. The uncertainty in the total activity added to each phantom was estimated to be $4.8 \%$ at the $95 \%$ confidence level, when all sources of error were added in quadrature.

The activity in the polyurethane remaining in the mixing cans was quantified, so that an absolute determination of the activity in the phantom could be made. Measurements were made with a 11.75-in.-diameter and 4-in.deep $\mathrm{NaI}$ detector. A counting geometry was used where the mixing cans were treated as point sources. The residual activity in the cans was determined to range from $4 \%$ to $8 \%$ of the activity in the phantoms.

The test radionuclide activities and errors for the BOMAB phantoms produced are listed in Table 3. 
TABLE 3. BOMAB Phantom Radionuclide Activities

\begin{tabular}{|c|c|c|c|}
\hline & Phantom & $\begin{array}{c}\text { Total Phantom } \\
\text { Activity }(n C i \pm 1 \sigma) \\
\end{array}$ & $\begin{array}{c}\text { Reference } \\
\text { Date }\end{array}$ \\
\hline (SRM & $\begin{array}{l}{ }^{137} \mathrm{CS} \\
4200-168)\end{array}$ & $306.8 \pm 7.5$ & $01-12-90$ \\
\hline & ${ }^{125} \mathrm{Sb}$ & $791.4 \pm 17.6$ & $03-01-90$ \\
\hline & ${ }^{154} \mathrm{Eu}$ & $1390 \pm 22$ & $"$ \\
\hline & $\begin{array}{l}{ }^{155} \mathrm{Eu} \\
4276 \mathrm{C}-49)\end{array}$ & $437.3 \pm 9.3$ & $"$ \\
\hline & ${ }^{40} \mathrm{~K}$ & $889.7 \pm 14.1$ & $04-01-90$ \\
\hline
\end{tabular}




\subsection{MEASUREMENT INTERCOMPARISON METHODS}

The photon emission spectra from the Fission Product phantom and BOMAB phantom were each analyzed for the quantitative response to the radionuclide activity loading and for the linear response as the phantom was scanned along the longitudinal axis. The methods used and the equipment involved in these measurements are described in this section.

\subsection{QUANTITATIVE MEASUREMENTS}

Three separate types of whole body counting instrument systems are housed at the Hanford In Vivo Radioassay and Research Facility: 1) a coaxial germanium detector array, 2) a $\mathrm{NaI}$ standup counter, and 3) a $\mathrm{NaI}$ shadow shield counting bed. These three systems (described below) were used to measure the quantitative response to the radionuclide activities loaded in the Fission Product and BOMAB phantoms. The results were compared with the existing calibration factors developed through Hanford's Whole Body Counting Program, which encompasses several decades of both human and phantom comparisons.

Each phantom tested was analyzed by repeated counts on each of the three systems to minimize any additional source of variation, such as phantom position or variable background contributions. The NaI results from the Eu/Sb phantom measurements were not suitable for quantitative analysis without spectrum stripping with its additional sources of error. Consequently, the measurement results of the Eu/Sb phantoms for the 1274-keV peak only are included in this study.

\subsubsection{Coaxial Germanium Detector Array}

The coaxial germanium detector array is routinely used to identify and quantify gamma-emitting radionuclides above $0.1 \mathrm{MeV}$. The array is operated with four large-volume germanium detectors positioned $1 \mathrm{~cm}$ below a Plexiglass sheet. The subject being counted lies in a supine position on the Plexiglass sheet. The detectors are mounted on a carriage that travels the length of the bed at a constant speed. The detector system is in a shielded cell with 12-in.-thick armor plate steel walls lined with a graded shield of lead, copper, and cadmium. The armor plate is pre-World War II steel from the 
battleship USS Indiana. Figure 4 illustrates the configuration of the coaxial germanium array.

The MDA for a 1200 -s count for ${ }^{137} \mathrm{Cs}$ is $\approx 0.9 \mathrm{nCi}$, and for ${ }^{154} \mathrm{Eu}$ it is $\approx 2$ $n C i$. The counting errors associated with phantom activities two magnitudes or more larger than the MDA are minimal.

\subsubsection{Vertical Array of Five NaI(TI) Detectors (Standup Counter)}

The standup counter consists of a column of five NaI detectors, mounted in a booth with $10 \mathrm{~cm}$ of lead shielding, as shown in Figure 5 . Four detectors are $93 / 8 \mathrm{in}$. in diameter and $4 \mathrm{in}$. deep. The fifth is $11-1 / 2 \mathrm{in}$. in diameter and $4 \mathrm{in}$. deep and is positioned over the lungs of the subject. The detectors are located behind the subject in an array that generally extends from the

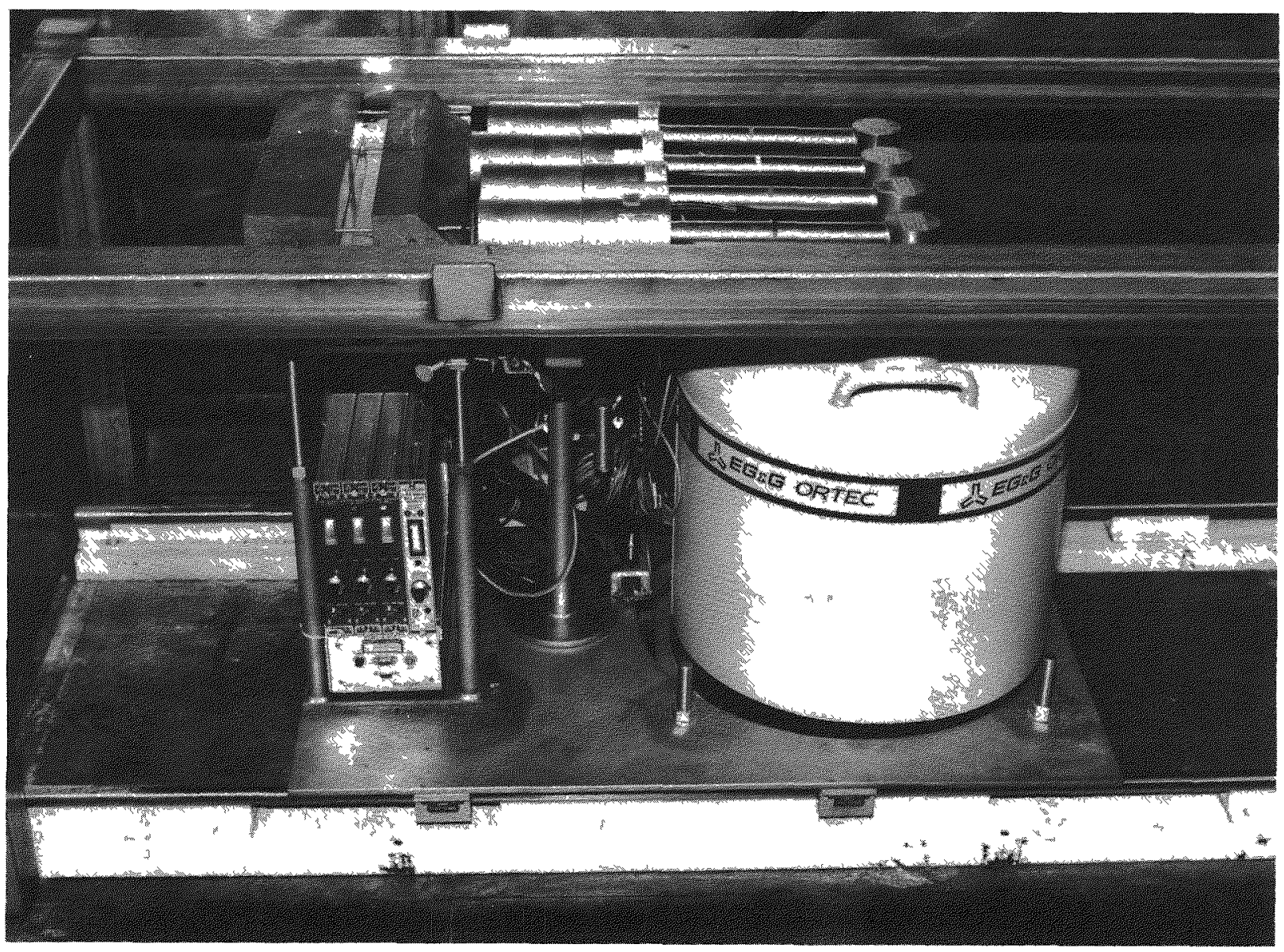

FIGURE 4. The Scanning Coaxial Germanium Detector Array 


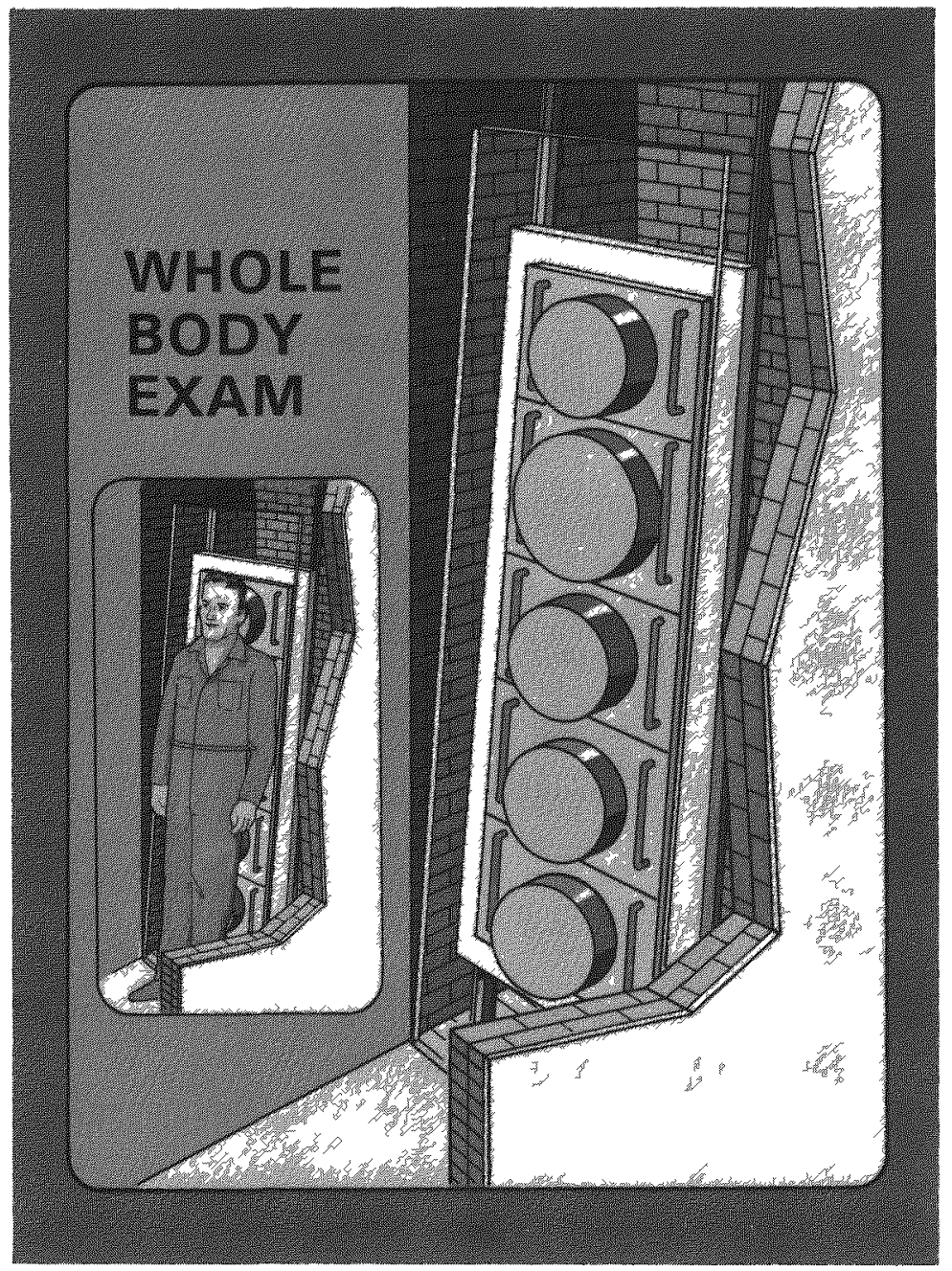

FIGURE 5. The Standup Counter with Counting Position (Inset)

head to the calves of the subject. The detector array can be vertically positioned to adjust to different body heights. The output includes an individual detector spectrum, except for the lower two detectors, which are coupled to provide a single output for the legs of the subject. Quantitative results are calculated from the summed spectra from a11 five detectors. The routine MDA for the system with a 200-s count time is $1.8 \mathrm{nCi}$ for ${ }^{137} \mathrm{Cs}$ and $4.3 \mathrm{nCi}$ for ${ }^{154} \mathrm{Eu}$. 


\subsubsection{Shadow Shield NaI Scanning Bed}

The shadow shield whole body counter is designed to be a low-background, transportable, and economical counter (Palmer and Roesch 1965). The shielding is placed in such a manner that a "shadow" is cast over the detector's sensitive area so that only scattered photons from non-subject areas reach the detector. The energy region above these Compton scattered events ( $300 \mathrm{keV}$ to $400 \mathrm{keV}$ ) then has a mean lower background contribution. This makes the system ideal for most radionuclides with high-energy gamma rays, such as fission products. Figure 6 illustrates the shadow shield configuration. The large crystal NaI(TI) detector measures 9-3/8 in. in diameter by $4 \mathrm{in}$. deep, and the system uses an energy calibration of $20 \mathrm{keV} / \mathrm{channel}$. The subject lies in a supine position on a sled that travels below the stationary detector. For a 1000 -s count, the MDA for ${ }^{137} \mathrm{Cs}$ is $2.2 \mathrm{nCi}$ and for ${ }^{154} \mathrm{Eu}$ it is $5.4 \mathrm{nCi}$. Using

\section{SHADOW SHIELD WHOLE BODY COUNTER}

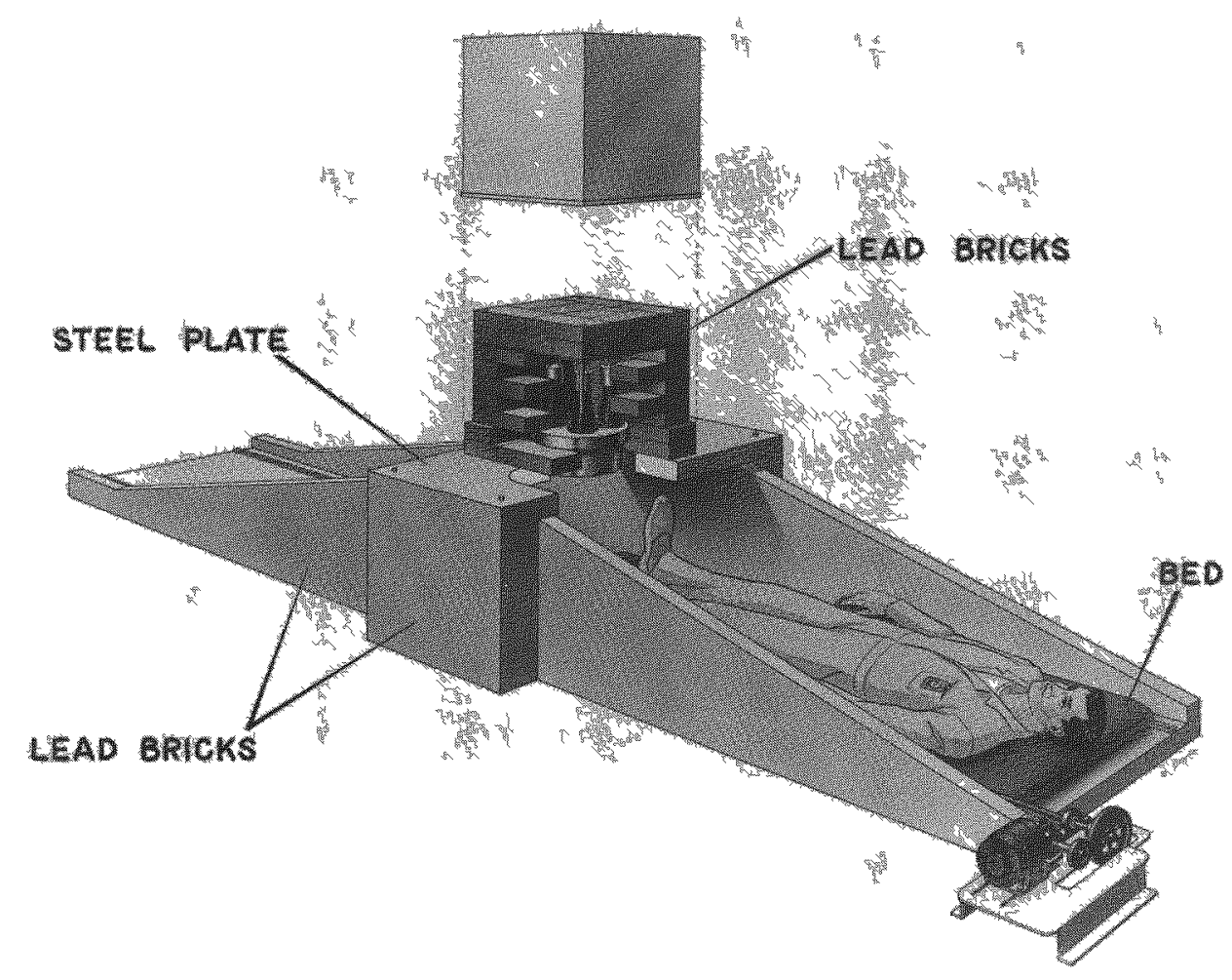

FIGURE 6. The Shadow Shield Scanning Bed 
this system, several studies were completed prior to 1965 using human radionuclide burdens (Palmer and Roesch 1965). These are the only human calibrations that have been documented for this type of counting system. The calibration factors developed from these studies are part of the documentation for the current PNL standard calibrations.

\subsection{DIFFERENTIAL LINEAR SCANNING}

Two methods of measuring the response to activity as the detectors scan down the length of the phantom were used. These two methods are described in the following sections. The measurements were accomplished in order to evaluate the longitudinal activity distribution in the phantoms and compare it with human results. Unfortunately no human data could be obtained that had sufficient activity to use this type of measurement, therefore only the two phantom types are compared. Variations in longitudinal distribution of activity can affect the response and therefore the results of whole body detector equipment. Certain whole body counting geometries are more sensitive to the distribution of radioactivity in the phantom (and thus in the human body also) than others. Scanning devices, where the detector is mechanicaliy driven along the longitudinal axis of the body, tend to smooth out the detector response of heterogenous activity distributions. They present no information on how the activity may be distributed, thus calibrations may not be accurate because the distribution changes for various intake and uptake situations. Array-type whole body detector systems using multiple fixed detectors tend to be more sensitive to the distribution of activity, especially when placed close to the body. Both of these factors need to be evaluated when using calibration phantoms.

\subsubsection{Five $\mathrm{NaI}(\mathrm{TI})$ Detector Vertical Array}

The first method of differential measurement along the phantom longitudinal axis employed the output from the five-detector $\mathrm{NaI}(\mathrm{TI})$ array standup counter. Four body area locations--the head, chest, abdomen, and legs--were measured and compared on the phantoms. This was accomplished by using each of the five separate detector responses saved separately (the lower two detectors viewing the thighs and calves were summed for a overall response for the legs) and generating a plot of each region throughout the energy 
spectrum. This resulted in a relative full-energy photopeak height for each of the four body areas. The plots are shown in the results section.

\subsubsection{Collimated 4-in.-by-4-in.-by-16-in. NaI Scanning Bed}

A second method of comparing the phantoms was to use the multichannel scaler (MCS) mode of the analyzer to measure phantom response as it was scanned by a 4-in.-by-4-in.-by-16-in. NaI collimated detector. This collimated detector can be seen to the left of the coaxial germanium detector array in Figure 4 . The system uses a single-channel analyzer to select the desired portion of the energy spectrum. Thus the longitudinal distribution of various gamma peaks can be graphically portrayed.

The result of an MCS scan shows the relative activity in the phantom as the collimated detector scans the length of the body. At this time the MCS scan cannot be used to determine activity quantitatively, but the scans are usefur in assessing quantitatively the distribution of activity within the body. Ideally, the scan of a phantom in such a manner will emulate the scan of a person exposed to the same radionuclide(s). The biological distribution of cesium, for example, should be uniformly dispersed within the soft tissues after uptake, and the phantom should mimic such a distribution. 


\subsection{RESULTS OF INTERCOMPARISON TESTS}

Each phantom type was compared with existing PNL calibration constants for the various counting systems and radionuclides. These calibration factors are listed in Table 4. The response of each detector system was also checked for errors, and repetitive counts were used to decrease any significant counting errors.

The current calibrations are based on many measurements of past human volunteers, previous water- and gel-filled BOMAB phantoms, other previous generation phantoms such as the REMAB, and intercalibrations between the PNL measurement systems and other DOE and international laboratories. Also incorporated into these calibration constants is a BOMAB-phantom-to-people correction factor that accounts for the difference in photon attenuation between water-filled BOMAB phantoms and people for certain radionuclide energies.

The computational algorithms based on measurements of the coaxial germanium detector array do not yet have a correction factor applied to them to account for the phantom-to-human-calibration difference. The detector array has been calibrated with the water- and polyurethane-filled BOMABs. PNL is pursuing methods whereby a human calibration can be cross-referenced using this equipment. A previous study with the shadow shield counter produced results for calibration factors that were determined using people who contained known amounts of ${ }^{42} \mathrm{~K}$ and ${ }^{137} \mathrm{Cs}$ (Palmer and Roesch 1965). These calibration factors are listed in Table 5.

TABLE 4. Calibration Factors Used for PNL Whole Body Counting Systems

\begin{tabular}{|c|c|c|c|}
\hline \multirow[b]{2}{*}{ System } & \multicolumn{3}{|c|}{$\begin{array}{l}\text { Calibration Factors } \\
\text { (cpm/nci in the body) }\end{array}$} \\
\hline & ${ }^{137} \mathrm{Cs}_{S}$ & ${ }^{154} \mathrm{Eu}$ & ${ }^{40} \mathrm{~K}$ \\
\hline Standup & $5 \overline{6.7}$ & $\overline{23.0}$ & $\overline{6.9}$ \\
\hline Coaxial germanium & 1.75 & 0.57 & 0.16 \\
\hline Shadow shield & 6.27 & 2.15 & 0.61 \\
\hline
\end{tabular}


TABLE 5. Calibrations and Comparison of Counting Efficiency with Body Size Using the Shadow Shield Counter ${ }^{(a)}$

\begin{tabular}{|c|c|c|c|c|}
\hline Subject & Nuclide & $\begin{array}{l}\text { Weight } \\
(\mathrm{kg})\end{array}$ & $\begin{array}{l}\text { Height } \\
(\mathrm{cm})\end{array}$ & $\begin{array}{l}\text { Calibration Factor } \\
(\mathrm{cpm} / \mathrm{nCi} \text { in the body) }\end{array}$ \\
\hline 1 & ${ }^{40} \mathrm{~K}$ & 84 & 170 & 0.629 \\
\hline 2 & ${ }^{40} k$ & 73 & 180 & 0.625 \\
\hline 3 & ${ }^{40} \mathrm{~K}$ & 89 & 183 & 0.638 \\
\hline 4 & ${ }^{40} \mathrm{~K}$ & 91 & 198 & 0.635 \\
\hline & & & Average & $0.632 \pm 0.006(1 \sigma)$ \\
\hline 5 & ${ }^{137} \mathrm{Cs}$ & 73 & 180 & 5.73 \\
\hline \multirow[t]{2}{*}{6} & ${ }^{137} \mathrm{Cs}$ & 89 & 183 & 5.56 \\
\hline & & & \multicolumn{2}{|c|}{ Average $5.65 \pm 0.12(1 \sigma)$} \\
\hline
\end{tabular}

(a) Adapted from Palmer and Roesch (1965).

The geometry and detector components from the 1965 data are similar enough to assume a certain confidence that the shadow shield calibration factors are still valid today. The use of these calibration factors assists in providing a "standard" against which to measure the two phantom types, without specifically stating that they are being compared with an absolute or primary standard, which does not exist at this time for in vivo systems.

\subsection{QUANTITATIVE RESULTS}

The results of measuring the ${ }^{137} C_{S}$ BOMAB phantom and Fission Product phantom are listed in Table 6 . The results were tabulated by the measured calibration factor for the phantom, which was then compared with the PNL calibration factor in parentheses. 
IABLE 6. Detector Results for Phantoms Loaded with ${ }^{137} \mathrm{Cs}$

\begin{tabular}{|c|c|c|}
\hline \multirow[b]{2}{*}{ System } & \multicolumn{2}{|c|}{ Calibration Factors (cpm/nCi) } \\
\hline & BOMAB Phantom & Fission Product Phantom \\
\hline Coaxial germanium & $1.69(3.4 \%$ low $)$ & $\begin{array}{l}1.34(23.4 \% \text { low }) \\
1.35(22.9 \% \text { low }) \text { face down }\end{array}$ \\
\hline Standup & 71.85 (26.7\% high) & $55.6 \quad(1.9 \%$ low $)$ \\
\hline Shadow Shield & $\begin{array}{l}6.24(0.5 \% \text { low }) \\
(10.4 \% \text { high })^{(a)}\end{array}$ & 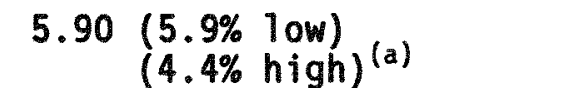 \\
\hline
\end{tabular}

(a) When compared with the 1962 human calibration factors (Table 5).

The results for the phantoms loaded with the Eu/Sb mixed gamma standard are listed in Table 7 and include the calibration factors measured and again being compared with the standard PNL calibration. Table 8 lists the results of the ${ }^{40} \mathrm{~K}$ measurements taken on the BOMAB and Fission Product phantoms.

The results indicated that detector system geometries and detector resolutions had a significant effect on some of the results obtained. The ${ }^{40} \mathrm{~K}$ results for the Fission Product phantom were affected by the interference of two photon energies from ${ }^{154} \mathrm{Eu}(1593 \mathrm{keV}$ and $1594 \mathrm{keV}$ ) when measured with the $\mathrm{NaI}$ detectors. Results for NaI systems are therefore not included in Table 8. For the same reason, the ${ }^{40} \mathrm{~K}$ response for the BOMAB phantom was not included.

IABLE 7. Results of the ${ }^{154}$ Eu Radionuclide Phantom Comparison Using the 1274-keV Photon

$\frac{\text { System }}{\text { Coaxial germanium }}$
Standup
Shadow shield

\begin{tabular}{cccc}
\multicolumn{2}{c}{ Calibration Factors $(\mathrm{cpm} / \mathrm{nCi})$} \\
\hline $\begin{array}{c}\text { BOMAB } \\
0.60(4.4 \% \text { high })\end{array}$ & & $\begin{array}{c}\text { Fission Product } \\
\text { Phantom }\end{array}$ \\
$26.3(13.4 \%$ high $)$ & & $23.5(15.8 \%$ low $)$ \\
$2.45(1.2 \%$ high $)$ \\
\end{tabular}


IABLE 8. Results of the ${ }^{40} \mathrm{~K}$ Radionuclide Phantom Comparison Calibration Factors (cpm/nCi)

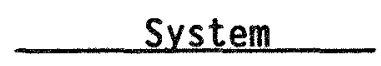

Coaxial germanium
BOMAB

$0.17(6.3 \% \mathrm{high})$
Fission Product

Phantom

$0.12(25.0 \%$ 10w)

As expected, the measurements made on the coaxial germanium array indicated that the BOMAB phantoms have a calibration factor within $3 \%$ to $6 \%$ of the PNL standard calibration factors for all the photon energies tested. Good correlation was expected because the existing calibrations for the standup counter, shadow shield counter, and the coaxial germanium array are in part based on liquid-filled and solid BOMAB phantom measurements with the activity homogeneously distributed. Since no correction factor was applied to the coaxial detector array to modify BOMAB phantom response for any inconsistencies with tissue these results most closely fit the test BOMAB phantom results. The results were within the overall probable error of whole body measurements, taking into account uncertainties associated with the activity, positioning, and Poisson counting errors. Generally, in vivo bioassay is thought to have a $5 \%$ to $10 \%$ probable error from these factors. For the Fission Product phantoms there was a significant low bias using the coaxial germanium array. When first noticed, this was thought to be due to the average discrete source locations being positioned more toward the posterior side than the anterior side of the phantom. To test this, the phantom was scanned in a reverse position. As indicated in Table 6 , the phantom was turned to its face-down position and scanned along the anterior surface. Measurements indicated that there was no significant change in response.

Part of the $8 \%$ to $25 \%$ low bias for the calibration factors in the Fission Product phantom can be attributed to the use of discrete sources rather than to the continuous volume source that was used in the BOMAB phantom. Radionuclides concentrated in the central body area have a greater attenuation per unit activity than those in a distributed source. This was verified by simulating the source loadings and phantom materials with shielding codes. This self-absorption effect is most evident at low photon energies, therefore the high-energy, $1274-\mathrm{keV}$ photon was used in the ${ }^{154} \mathrm{Eu}$ phantom comparison results to minimize this. The low bias associated with 
this attenuation was even more significant using the lower energies of the ${ }^{154} \mathrm{Eu},{ }^{155} \mathrm{Eu}$, and ${ }^{125} \mathrm{Sb}$ mixed gamma standard due to increased interaction coefficients.

The polyurethane BOMAB phantom response was higher than the current PNL calibration factors for the systems (the standup and shadow shield counters) that use a correction factor based on water- and gel-filled BOMAB measurements. The removal of this correction factor from the PNL calibration factors used on these systems caused the polyurethane BOMAB results to correspond we11 with them, i.e., when the polyurethane BOMAB phantom was compared solely with water-filled BOMAB phantom calibrations there is good agreement.

The $B O M A B$ phantom source configuration (uniformly distributed source) most closely conforms to the known physicochemical properties of cesium and potassium in the human body. The response was somewhat higher than the PNL calibration, and it is thought that this was due to a different photon transmission quality of the formulation used in the BOMAB phantom when compared with human tissue.

\subsection{DIFFERENTIAL LINEAR SCAN RESULTS}

Two different types of linear activity measurements were performed on the phantoms. The purpose of these measurements was to evaluate the detector response to the activity in phantom body regions, and to correlate the response and geometry to the known activity in each phantom part. From this it could be determined how well each phantom type emulates a uniform whole body radionuclide distribution.

From the relative output of the four regions of the standup $\mathrm{NaI}$ (TI) whole body counter, a general picture of the relative amounts of activity in the phantoms was constructed. The detector response was compared on a relative output basis and the results were plotted. The percentage of total activity distributed in the head, chest, abdomen, and leg regions of the phantoms as compared with the measured response for each region using the standup scanner is shown in Table 9. Included in the table are results of the average response of 15 human cesium burdens identified at PNL in 1990. 
TABLE 9. Percent Activity in Body Regions of Two Phantoms and Humans ${ }^{(a)}$

\begin{tabular}{|c|c|c|c|c|c|}
\hline \multirow[b]{2}{*}{$\begin{array}{c}\text { Body } \\
\text { Region }\end{array}$} & \multicolumn{2}{|c|}{ BOMAB Phantom } & \multicolumn{2}{|c|}{ Fission Product Phantom } & \multirow{2}{*}{$\begin{array}{l}\text { Human Study } \\
\% \text { Activjty } \\
\text { Humans (b) }\end{array}$} \\
\hline & $\begin{array}{l}\% \text { Activity } \\
\text { by Weight }\end{array}$ & $\begin{array}{l}\% \text { Activity } \\
\text { Measured }\end{array}$ & $\begin{array}{l}\% \text { Activity } \\
\text { Measured }\end{array}$ & $\begin{array}{l}\text { in F.P. } \\
\text { Phantom } \\
\end{array}$ & \\
\hline Head $(c)$ & 12 & 7.6 & 5 & 0 & $9.99 \pm 2.8$ \\
\hline Chest $^{(d)}$ & 32.5 & 34.4 & 39.5 & 67 & $34.5 \pm 3$ \\
\hline Abdomen ${ }^{(e)}$ & 20.5 & 22.5 & 22 & & $22.3 \pm 2.94$ \\
\hline Legs & 35 & 35.4 & 33 & 38.7 & $33.4 \pm 2.95$ \\
\hline
\end{tabular}

(a) Measurements made with a vertical array of five NaI detectors.

(b) Errors are the statistical variation of the mean of 15 positive human measurements.

(c) Includes head and neck containers for BOMAB phantom.

(d) Includes the contribution from the upper portion of the limbs.

(e) Includes the contribution from the lower portion of the limbs.

The average of two spectra $\left({ }^{154} \mathrm{Eu}\right.$ and $\left.{ }^{137} \mathrm{CS}\right)$ for each phantom type was used in the table.

There is no detector balancing to ensure that each of the five detectors produces equal response per unit activity. Interference occurs between detectors because there is no collimation. Consequently, one can only use the results as an estimate of relative response to activity in the general body areas of the phantom. Figure 7 a shows a plot of the result of the BOMAB phantom analysis using the standup counter, and Figure $7 \mathrm{~b}$ shows a plot of the results of the Fission Product phantom analysis. A typical human result for a ${ }^{137} \mathrm{Cs}$ deposition is given in Figure $7 \mathrm{c}$ for comparison.

The responses to both the BOMAB and the Fission Product phantoms using the vertical array of five NaI detectors were representative of the activity placement in the body regions, and their overall percent response per body region was similar. The BOMAB phantom response for the head region was somewhat high, possibly due to detector location (the assembled BOMAB is taller than the Fission Product phantom). The Fission Product phantom leg response was similarly low, due to attenuation of the photons from a point source located at the center of the thighs and calves of the Fission Product 


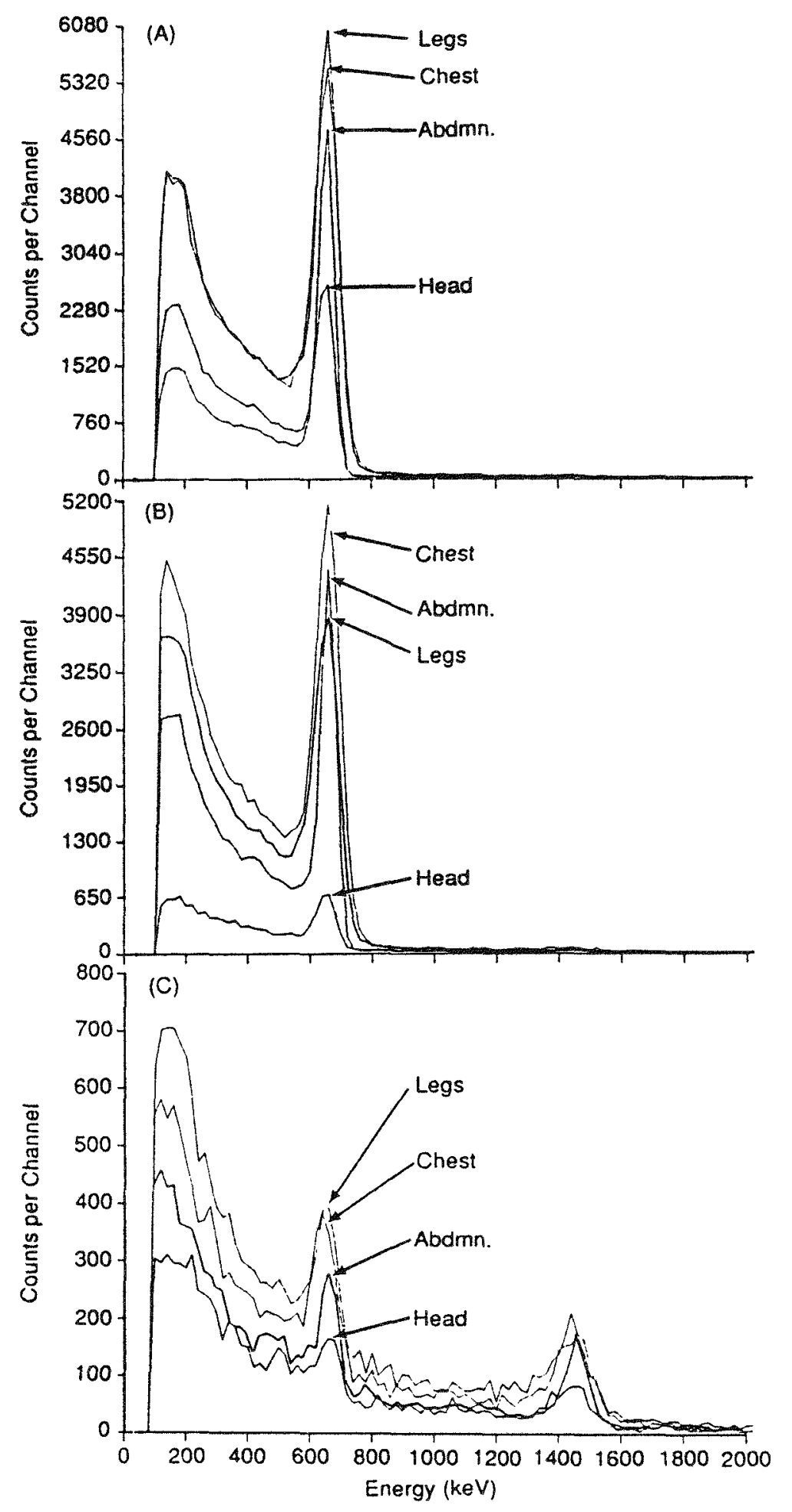

FIGURE 7. Response of Standup Counter to Four Measured Regions of

(a) the BOMAB Phantom, (b) the Fission Product Phantom, and (c) a $12-\mathrm{nC}$ i Human ${ }^{137} \mathrm{Cs}$ Deposition 
phantom. It was in this region that the discrete sources were most deeply buried, which will tend to enhance the difference between a point source covered by non-source tissue-equivalent (TE) material and a distributed tissue-equivalent source. Even though there were no sources located in the head for the Fission Product phantom, the head area detector response was similar to both a human measurement and the BOMAB result.

The detector response to the activity distributions in both phantoms was similar to the mean response to the ${ }^{137}$ Cs activity distribution in 15 human cases measured in 1990 at PNL. The internal depositions of ${ }^{137} \mathrm{Cs}$ in the 15 human deposition cases ranged from $4.6 \mathrm{nCi}$ to $13.9 \mathrm{nCi}$. Because the distribution of discrete sources in the body cavity of the Fission Product phantom were throughout the various organs and no real boundary of upper or lower thorax existed, results for each body area couldn't be differentiated. The activities for the chest and abdomen of the Fission Product phantom are thus combined in Table 9.

Linear scan measurements of a second type were completed using the coaxial germanium detector array. An auxiliary collimated NaI detector (see Section 3.1.2) was used to scan along the longitudinal body axis of the phantom. The measurements were limited to the photon energy region of interest of the primary test radionuclides for each phantom. For the Eu/Sb phantom this region included the gamma ray peak at $1274 \mathrm{keV}$. Using this highenergy photon of the mixed gamma standard reduced the effect of point source loadings being attenuated by large overlying areas of polyurethane.

The resulting scan of the region of interest for each phantom is shown in Figures 8 and 9. No equivalent human ${ }^{137} \mathrm{Cs}$ burdens have been measured on this system to date, so a comparison with a known uniformly distributed cesium burden in people couldn't be made. The sharp peaks in Figure 9 are markers used to denote the ends of the Fission Product phantom.

The linear scan comparison of the phantoms distinctly illustrated the limitations of the discrete source matrix used in the Fission Product phantom. Where there is a uniform response proportional to the mass of the region being scanned for the BOMAB phantom, distinct areas are evident in the Fission Product phantom measurement that show low activity. Peaks relate to the concentrated areas where source capsules had been placed. The head, neck, 
pelvis, and knees showed distinct response minimums; no activity could be placed in these regions.

\subsection{PHYSICAL DURABILITY AND DESIGN}

Physical attributes of the calibration phantoms were also evaluated in order to determine if there were deficiencies that might influence a successful DOELAP testing program. The overall design of the phantoms was studied. The characteristics of ease-of-use and durability of the calibration phantoms were also evaluated. These attributes were found to be important in a round-robin testing program that would require dozens of routine shipments between the participating laboratories. A history of incidents of damage during shipping further emphasized the need for a sturdy, durable design for the calibration phantoms intended for use in a DOELAP accreditation program. The phantom should also have an easily repeatable setup geometry and the radionuclide loading should not be too difficult to reproduce.

Several difficulties were noted with the Fission Product phantom when loading it with discrete source capsules. The capsule material was flexible and sealing the capsule after the source was inserted was difficult. This led to several instances of exposed radioactive material outside of the capsules. The capsules are difficult to manipulate into the phantom body parts. Several capsules were destroyed in the process of inserting them. The capsules were very difficult to remove once they were in place, virtually ensuring that the sources were permanent. Duplicating the discrete source locations in the Fission Product phantom is important to assure that subsequent calibration phantoms emit the same photon fluence. This is difficult to achieve in the Fission Product phantom because each source capsule must be located precisely in the drilled holes provided in the phantom, and the capsules can become stuck inside. The Adaprene material (a polyurethane derivative) used for TE properties is not durable. During this study a joint ripped after only a few uses, and subsequently affected the counting geometry of the lower leg. The blank Adaprene plugs tend to fall out during transit or use of the phantom once they have been disturbed for locating sources. Although the Fission Product phantoms have not been noted yet to deform or warp with age, the previous generation LLNL and Realistic torso phantoms of similar material 


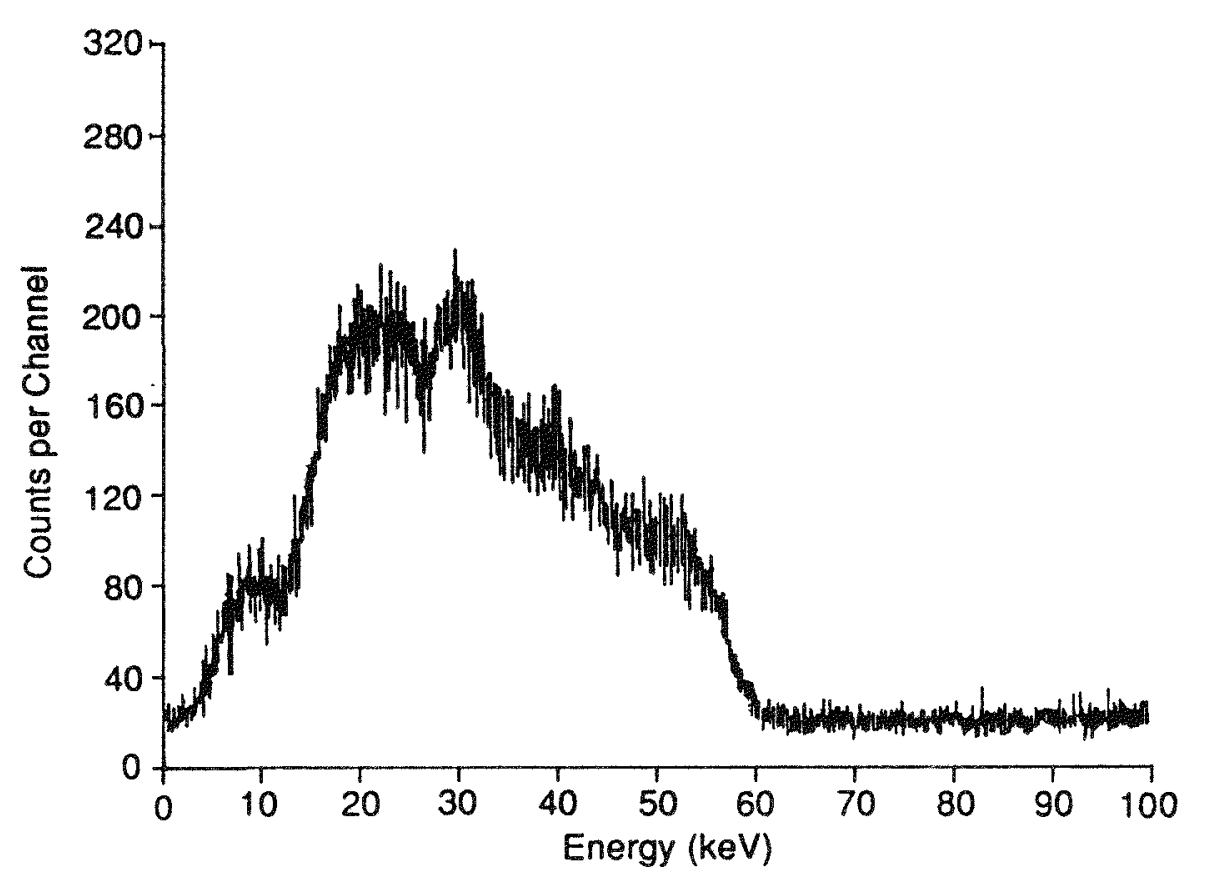

FIGURE 8. Collimated Linear Scan of the ${ }^{154} \mathrm{EU}(1274-\mathrm{keV})$ BOMAB Phantom

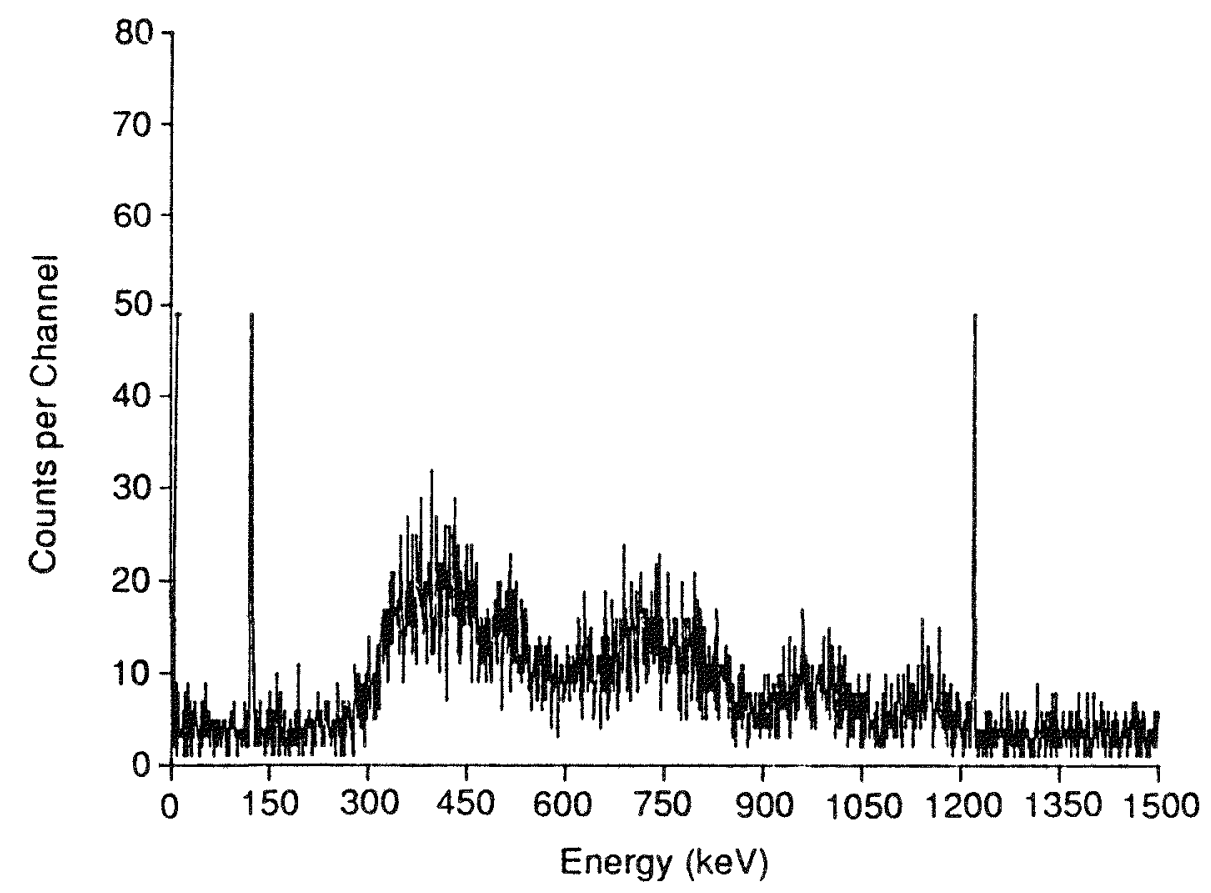

FIGURE 9. Collimated Linear Scan of the ${ }^{154}$ Eu Fission Product Phantom 
have been observed to lose their shape in the chest cover area, thus not providing a uniform chest wall for sources located in the mock internal organs of the phantom. It can be expected that this will also occur to Fission Product phantoms over time.

The two Fission Product phantoms tested in this study differed in weight by approximately $5 \%$; one weighed $77.9 \mathrm{~kg}$ and the other $82.0 \mathrm{~kg}$. This may have attributed to the differences noted in calibration factors. From the standpoint of product quality assurance, assuring a uniform density of material is essential in the manufacture of phantoms, especially when used with low-energy gamma emitters.

The limitations of the Fission Product phantom more than outweighed its advantages, for a DOELAP testing program. The anatomical features simulate human features, but there is no indication that it realistically provides a calibration similar to humans. It is noticeably less durable than the BOMAB phantom, which, with a polyurethane filler, is very durable and does not lose any calibration radioactivity. In over two years of use there have been no noted age-related effects on the BOMAB materials. The filler risers have been known to crack and break, but because no material is lost when using a polyurethane formulation this still does not invalidate the calibration of the phantom.

BOMAB phantom limitations were noted using the polyurethane formulation as a fill material. The exothermic reaction during curing of the polymer caused bubbles along the interface between the polyethylene container and the polyurethane mixture. These were generally minor surface voids, which, with additional care in casting, could be eliminated. A gravimetric-based production method is necessary to ensure the exact quantities of SRM in the phantom are known. The method that was used to determine the residual SRM activity not contained in the BOMABs after pouring and casting the polyurethane was inadequate. It consisted of counting the residual activity in the mixing containers. This added another source of error in the final stated activity of the BOMABs. 


\subsection{CONCLUSIONS}

Using PNL whole body counting equipment, this study in part determined the differences in calibration factors for the BOMAB and the Fission Product calibration phantoms. It also compared the equipment response between phantoms and known human data. There were significant differences in each phantom's measured calibration factors, which, if accepted as accurate human calibrations could then cause errors in in vivo bioassay of humans. Without any necessary human calibration studies to correct for the discrepancies noted, laboratories could incorporate incorrect phantom calibration factors into bioassay measurement procedures. Ideally, a calibration phantom should not be significantly different from human response at all photon energies of interest. Practically, this condition has yet to be met.

Each phantom type has advantages for use in different calibration situations. The Fission Product phantom calibration factors were lower $(\mathrm{cpm} / \mathrm{nCi}$ ) than the BOMAB phantom calibration factors for all three counting systems for both ${ }^{137} \mathrm{Cs}$ and ${ }^{154} \mathrm{Eu}$. When results were compared with the 1962 study of ${ }^{137} \mathrm{Cs}$ contaminated people (Palmer and Roesch 1965), the Fission Product phantom had a closer calibration to human response than the BOMAB phantom.

Reasons for the lower calibration factors for all three counting systems for the Fission Product phantom were: 1) the difference in mass between the two phantom types (the BOMAB phantoms weighed $74 \mathrm{~kg}$ and the Fission Product phantoms averaged $80 \mathrm{~kg}$ ), and 2) the material used in the Fission Product phantom allows less transmission of photons than the Hysol polyurethane formulation. Additional filler materials added to the polyurethane to increase the effective atomic weight and electron density may be necessary to decrease the transmission of photons through the Hysol polyurethane material, because it is somewhat less transparent to photons than human tissue. Further transmission studies for the material using a wide range of photon energies should be undertaken in order to characterize the TE formulation. These are planned as part of developing phantoms for DOE programs.

The calibration factors PNL uses for in vivo bioassay are based partially on previous generation water-filled and polyurethane BOMAB phantoms. 
Other factors used in calibrating PNL's in vivo detection equipment are human measurements and extrapolation of detector responses from one system to another. In trying to improve the accuracy of detection equipment, laboratories often use measurements that, because of the confidentiality of results, are not published. The use of human subjects is usually a difficult proposition for policy considerations, so laboratories must make the best of any data that exist. This means a heavy reliance on calibration phantoms. The comparisons with the PNL calibrations for the BOMAB phantom showed close agreement on one measurement system -- the coaxial germanium array. For the other systems, the Fission Product phantom response was closer to agreement with PNL calibration factors. Because the germanium array is a newer system, it has relied heavily on calibrations using the BOMAB type of phantom.

The comparison with the human data was made because the counting geometry and configuration of the shadow shield detector system is the same as the system used in 1965. Thus it was assumed that calibration factors were still valid. When comparing the phantom results to these data, it is evident that the Fission Product phantom has a closer calibration than the BOMAB phantom. Because of the geometry-dependent response of each counting system though, without human data to compare on the standup and scanning germanium systems one cannot make this conclusion for them also.

Limitations of the source geometries that can be attained in the Fission Product phantom were noted when attempting to model a uniformly distributed radionuclide. These limitations caused an unequal response down the length of the phantom when it was scanned; the detector response had no correlation with phantom physiological dimensions or mass. It would be possible to compensate for these discrepancies by weighting the discrete source loadings toward areas in the phantom that had low detector response, but this is not in keeping with a "Standard Phantom" with a certifiable amount of radioactivity incorporated. As was seen in the results here, the phantom would cause detector response that was also geometry-dependent. Certain whole body counting systems would over- or under-compensate to the weighted loading. The necessary trial and error process needed to emulate the human response with a weighted non-uniform distribution of radionuclide couldn't be completed without current human data on radionuclide distributions. 
The BOMAB phantom with its uniform distribution of radioactive material in the TE matrix, showed a much more uniform linear response when scanned. The costs associated with producing a TE material and casting it in the BOMAB containers is much less than the Fission Product phantom costs. Although it cannot be reused, it assures a non-changeable source geometry. It did not produce calibration factors that were as close as the Fission Product phantom results were to human data. An evaluation of the TE properties of the polyurethane is in progress at PNL.

The evaluation of the phantoms from the standpoint of use and fabrication of the source loading showed many more limitations and potential problems with the Fission Product phantom than with the BOMAB phantom. The difficulties in adding and removing sources were noted, as was the Adaprene material's proneness to damage. The durability and repeatability of source loadings in the BOMAB phantom design are of importance in the successful completion of DOELAP in vivo bioassay testing programs. These characteristics allow a phantom to survive the rigorous conditions involved in DOELAP roundrobin testing.

Despite how well the Fission Product phantom corresponded to both PNL calibration factors and past studies of people with uniformly distributed radionuclide burdens ( $\mathrm{Palmer}$ and Roesch 1965), its proper use seemed to be more directed towards phantom/human response research and a laboratory environment of precise technical measurements. The Fission Product phantom has unlimited configurations available for loading various organs for calibration measurements. The discrete source loadings for the torso and limbs are less satisfactory.

Due to the numerous variables inherent in measuring radionuclide burdens in people, such as positioning errors, correct background analys is of Compton events, and biological variability of humans, an exact duplicate of human response by a phantom cannot be obtained. At least in the foreseeable future there will be an inherent variation between measurements of $5 \%$ to $10 \%$. Participation in careful human studies (such as those undertaken in Harwe11, Great Britain), or cooperation with Hanford Environmental Health Foundation studies of human donors would be of tremendous value in determining systemspecific calibrations for in vivo bioassay and in determining just how 
important the geometry of the detector/source configuration in phantoms is. The reliance on 25-year-old data cannot be continued for new generation equipment because no calibration to these data can be extrapolated. This study helped exhibit the limitations of any phantom in standing as a reference calibration alone for different detection equipment and varying geometries. Therefore, development of phantom-to-people correction factors for modern counting systems, e.g., germanium detectors, is highly desirable.

A phantom that is well characterized, has a repeatable and durable source geometry, and can endure physically strenuous conditions of round-robin testing is the most appropriate calibration phantom for the DOELAP performance testing program. The BOMAB phantom with a polyurethane-mix, uniform radionuclide-loading will meet these criteria. 


\subsection{REFERENCES}

American National Standards Institute (ANSI). 1989. "Performance Criteria for Bioassay." Draft ANSI N13.30-1989, New York, New York.

Griffith, R. V., P. N. Dean, A. L. Anderson, and J. C. Fisher. 1978. Fabrication of a Tissue-Equivalent Torso Phantom for Intercalibration of In-Vivo Transuranic-Radionuclide Counting Facilities. UCRL-80343, Lawrence Livermore National Laboratory, Livermore, California.

International Commission on Radiological Protection (ICRP). 1974 Report of the Task Group on Reference Man. ICRP Publication 23, Pergamon Press, New York, New York.

International Commission on Radiation Units and Measurements (ICRU). 1989. Tissue Substitutes in Radiation Dosimetry and Measurement. ICRU Report 44, Bethesda, Maryland.

Maclellan, J. A., R. A. Traub, and P. C. 01 sen. 1990. Performance Testing of Radiobioassay Laboratories: In Vivo Measurements, Final Report. PNL-7307, Pacific Northwest Laboratory, Richland, Washington.

Palmer, H. E., and W. C. Roesch. 1965. "A Shadow Shield Whole-Body Counter." Health Phys. 11(11):1213-1219.

Robinson, A. V., D. R. Fisher, W. D. Reece, and J. A. MacLell an. 1986. Performance Testing of Radiobioassay Laboratories: In Vivo Measurements, Pilot Study Report. PNL-5840, Pacific Northwest Laboratory, Richland, Washington.

Scherpelz, R. I., and J. A. MacLellan. 1987. Comparisons of Uniform and Discrete Source Distributions for Use in Bioassay Laboratory Performance Testing. PNL-6303, Pacific Northwest Laboratory, Richland, Washington.

U.S. Department of Energy (DOE). 1989. Department of Energy Laboratory Accreditation Program (DOELAP) for Personnel Dosimetry, DOE 5480.15, Washington, D.C. 


\section{DISTRIBUTION}

No. of

Copies

\section{OFFSITE}

12 DOE/Office of Scientific and Technical Information

\section{DOE Headquarters}

C. R. Jones

Office of Health

EH-41

Washington, DC 20545

$5 \quad$ R. M. Loesch

Office of Health

\section{$\mathrm{EH}-40$}

U.S. Department of Energy

Washington, DC 20545

D. R. Nelson

Office of Safety Policy and Standards

EH-352

U.S. Department of Energy

Washington, DC 20545

DOE Albuquerque Operations

Office

Manager, Health Physics

Pantex Plant

Mason \& Hanger--Silas Mason

Co., Inc.

P.0. Box 30020

Amari110, TX 79177
No. of

Copies

S. W. Alderson

Radiology Support Devices, Inc.

1904 E. Dominguez St.

Long Beach, CA 90810

R. Brake

Los Alamos National Laboratory

LANL K483

Los Alamos, NM 87545

R. Devine

Los Alamos National Laboratory

Los Alamos, NM 87545

DOE Chicago Operations office

L. V. Coulson

Fermi National Accelerator Laboratory

P.0. Box 500

Batavia, IL 60510

C. Sun

Radiological Sciences

Division, B1dg. 703M

Brookhaven National Laboratory

Upton, NY 11973

D. Toohey

Argonne National Laboratory

9800 S. Cass Ave.

Argonne, IL 60439

H. Spitz

Mound Laboratory

Monsanto Research Corporation

P.0. Box 32

Miamisburg, OH 45342 
No. of

Copies

DOE Idaho Operations office

J. Martin

U.S. Department of Energy

Idaho Operations office

785 DOE P1ace

Idaho Falls, ID 83402

B. L. Rich

EG\&G Idaho

P.0. Box 1625

Idaho Falls, ID 83401

A. N. Tschaeche

WINCO

MS 5209

P.0. Box 4000

Idaho Falls, ID 83403

T. Taylor

DOE Idaho Falls Operations Office

RESL, B1dg. CS -690

Idaho Falls, ID 83402

G. E. Grothaus

MS-4149

DOE Idaho Operations Office

Idaho Falls, ID 83402

DOE Oak Ridge Operations

office

R. J. Cloutier

Oak Ridge Associated

Universities

P.0. Box 117

Oak Ridge, TN 37831-0117

J. W. Neton

Westinghouse Materials Co. of Ohio

P.0. Box 398704

Cincinnati, $\mathrm{OH} \quad 45239$
No. of

Copies

T. M, Jel inek

U.S. Department of Energy

Oak Ridge Operations Office

P.0. Box E

Oak Ridge, TN 37831

M. Thein

Oak Ridge National Laboratory ORNL-MMES

P.0. BoX 2008

4500S, MS - 6105

Oak Ridge, TN 37831-6105

F. K. Toml inson

EG\&G Mound Applied Tech.

Mound 1

P.0. Box $3000, A-190$

Miamisburg, $\mathrm{OH} 45343$

E. R. Wagner

Portsmouth Gaseous Diffusion Plant

Martin Marietta Energy

Systems

P.0. Box 628

Piketon, $\mathrm{OH} 45661$

H. D. Whitehead

Oak Ridge Gaseous Diffusion Plant

P.0. Box 2003

Oak Ridge, TN 37831-7403

DOE San Francisco Operations

Office

G. W. Campbe11

Lawrence Livermore Nationa] Laboratory

P.0. Box 808, MSL382

Livermore, CA 94550 
No. of

Copies

D. A. Kruchten

Lawrence Livermore National Laboratory

P.0. Box 808

Livermore, CA 94550

W. Warner

U.S. Department of Energy

San Francisco Operations Office

1333 Broadway

Oakl and, CA 94612

DOE Savannah River Operations Office

J. R. Watts

Westinghouse Savannah River

Co., Inc.

P.0. Box 616

Aiken, SC 29801

National Institute of

Standards and Technology

K. Innes

National Institute of Standards and Technology

B1dg 245, Rm. C229

Gaithersburg, MD 20899

\section{Canada}

G. H. Kramer

Human Monitoring Laboratory

BRMD

775 Brookfield Rd.

Ottawa, Ontario KIA 1C1 Canada

Nuclear Regulatory Commission

A. K. Roeckle in

Office of Regulatory Research

U.S. Nuclear Regulatory

Commission

Washington, DC 20555
No. of

Copies

S. A. McGuire

Radiation Protection and Health Effects

Division of Regulatory Applications

Office of Nuclear Regulatory Research

U.S. Nuclear Regulatory Commision

Washington, DC 20555

ONSITE

DOE Field Office, Richland

D. T. Evans

49 Pacific Northwest Laboratory

L. G. Faust

D. R. Fisher

R. L. Hill

A. C. James

J. R. Johnson

T. P. Lynch (10)

J. A. MacLel1an

J. C. McDonald (3)

P. C. Olsen (10)

H. E. Palmer

G. A. Rieksts

J. M. Selby

K. L. Soldat

P. S. Stansbury (3)

K. L. Swinth

Health Physics Department

Library

Publishing Coordination (2)

Technical Report Files (5) 